\title{
Impact of ectoparasites on the demography of a small reef fish
}

\author{
Rachel J. Finley*, Graham E. Forrester \\ Department of Biological Sciences, 100 Flagg Road, University of Rhode Island, Kingston, Rhode Island 02881-0816, USA
}

\begin{abstract}
In marine systems, empirical studies demonstrating effects of macroparasites on host population dynamics are relatively few. We tested the effects of a copepod macroparasite infecting the gills of a small coral reef fish, the bridled goby Coryphopterus glaucofraenum. Fish that were naturally infected and uninfected were tagged as individuals and tracked in the field for 5 mo. Parasitism was associated with an increase in gill ventilation rate, and a reduction in feeding. More importantly, parasitized fish showed significantly reduced growth (by 66\%) and gonad mass (by 68\%) compared to uninfected fish, and parasitism increased instantaneous mortality by a factor of 1.8. Since the prevalence of infection was higher in areas of high goby density, parasiteinduced mortality is a possible cause of host density dependence. These results imply a major effect of parasitism on host population dynamics and suggest that parasitism warrants closer attention by marine ecologists.
\end{abstract}

KEY WORDS: Pharodes tortugensis - Coryphopterus glaucofraenum · Host-parasite interaction · Parasitic gill copepod

Resale or republication not permitted without written consent of the publisher

Empirical studies demonstrating effects of parasites on host population dynamics are relatively few, and have lagged behind theoretical explorations of this subject (Scott \& Dobson 1989, Dobson \& Hudson 1992, Grenfell \& Dobson 1995, Grenfell \& Gulland 1995). Of the empirical studies conducted, most have focused on microparasites, whereas evidence for impacts of macroparasites on host dynamics is particularly sparse (Scot \& Dobson 1989, May 1993, Grenfell \& Dobson 1995). Field research on both sorts of parasites has been conducted primarily in terrestrial habitats (Dobson \& Hudson 1992, Gulland et al. 1993, Grenfell \& Dobson 1995, Hudson et al. 1998). In marine benthic systems, most explanations for population dynamics have focused on the effects of variable larval recruitment coupled with predator-prey and competitive interactions among adults (e.g. Caley et al. 1996, Bertness et al. 2001). Work on reef fishes reflects the general lack of attention to potential impacts of parasitism on host population dynamics in marine systems (Sale 1991, Caley et al. 1996). Despite lack of study, there is clear potential for parasites to affect fish populations because they support diverse parasite communities (Poulin 1995), many of which have pathogenic effects (Sindermann 1987). Theoretical studies (Dobson \& May 1987), physiological studies (Dawson 1998, MacKenzie et al. 1998, Nolan et al. 1999), and studies of captive fish (Sindermann 1987) attest to the potential impact of parasites on these host populations, though the applicability of these results to wild populations is uncertain (but see Adlard \& Lester 1994).

Direct evidence for impacts of parasites on wild fish populations may be scarce in part because parasites are easily overlooked and because we cannot routinely follow hosts of known infection status in the field (Dobson \& May 1987, Scott \& Dobson 1989, Grenfell \& Dobson 1995). Here we test the effects of an external macroparasite on the demography of a small reef fish in a system where hosts can be tracked as individuals, and parasitized hosts can be recognized visually. We were thus able to directly measure demographic rates of parasitized and unparasitized fishes in the field.

Materials and methods. Study system: Host-parasite interactions were studied near Guana Island (64 $35^{\prime} \mathrm{W}$, $\left.18^{\circ} 29^{\prime} \mathrm{N}\right)$, British Virgin Islands. The host species, the bridled goby Coryphopterus glaucofraenum Gill, is a small benthic fish that occurs throughout the Caribbean. Larvae are planktonic and settle to reef habitats at $\sim 8 \mathrm{~mm}$ standard length (SL). Juveniles mature into females at $\sim 25 \mathrm{~mm} \mathrm{SL}$, and change sex to become males at $\sim 35 \mathrm{~mm}$ SL (Cole \& Shapiro 1992). Gobies occupy small home ranges $\left(<4 \mathrm{~m}^{2}\right)$ in areas of interspersed sand and reef and are aggressive to neighbors. They feed on sand-dwelling invertebrates, and use crevices in the reef as shelter from predators.

The parasitic copepod Pharodes tortugensis Wilson infects the gill cavity of bridled gobies near Guana 
Island (R. Finley pers. obs.) and at least 4 other fish species elsewhere (Ho 1971). The life cycle of P. tortugensis has not been described completely, but the copepods are likely to have a simple life cycle with only one host during their lives (Kabata 1981). Males and juveniles cannot swim if detached from the host (R. Finley pers. obs.) and mature female $P$. tortugensis burrow their heads into the body wall of the gill cavity (Ho 1971), reducing the likelihood of host-to-host movement after the initial infection.

Bridled gobies infected with Pharodes tortugensis have a swollen operculum. On 23 June 2001 we used this criterion to visually diagnose parasitism underwater, and checked the accuracy of this method by subsequently capturing and dissecting fish $(\mathrm{n}=106)$ to verify their infection status. Uninfected fish were reliably identified $92 \%$ of the time (46 of 50 correct), but identification of infected fish was less certain, $84 \%$ of the time (47 of 56 correct). Most infected fish were large juveniles and females (16 to $30 \mathrm{~mm} \mathrm{SL}$ ). The mean number of copepods per infected fish was 6.99 (range $=1$ to $19, \mathrm{SD}=3.97, \mathrm{n}=126$ ) with more male and juvenile copepods $(5.63 \pm 3.77 \mathrm{SD})$ than females $(1.74 \pm 0.52 \mathrm{SD})$ per infection. As with most macroparasite infections, the frequency of infection intensity was overdispersed in the population (Lester 1984) and was well described by the negative binomial distribution $\left(\chi^{2}{ }_{16}=9.45, \mathrm{n}=126, \mathrm{p}=0.25\right)$. Mean goby density at 9 sites around Guana Island in July and August 2002 varied from 2.15 to $4.55 \mathrm{~m}^{-2}$ and the prevalence of copepod infection ranged from 2 to $19 \%$ (Table 1).

Effects of parasites on host behavior and demography: Effects of Pharodes tortugensis on gobies were tested at a site $\left(560 \mathrm{~m}^{2}\right)$ within the White Bay I location (Table 1). This site is part of a large continuous reef and so was not isolated from surrounding habitat.

Table 1. Coryphopterus glaucofraenum. Mean (SD) density and prevalence of parasitized individuals at 9 sites in the British Virgin Islands based on visual census of 5 to 10 randomly located $4 \mathrm{~m}^{2}$ transects per site. White Bay I was the site used to study the effects of parasites on host behavior and demography

\begin{tabular}{|llrc|}
\hline Island & \multicolumn{1}{c}{ Site } & $\begin{array}{c}\text { Density } \\
\text { (ind. }{ }^{-2} \text { ) }\end{array}$ & $\begin{array}{c}\text { Prevalence } \\
\text { (\% parasitized) }\end{array}$ \\
\hline Guana & White Bay I & $4.68(2.64)$ & $14.44(11.32)$ \\
& White Bay II & $5.03(1.37)$ & $15.95(11.67)$ \\
& Harris Ghut & $5.25(1.24)$ & $10.68(7.81)$ \\
& Monkey Point & $7.60(2.45)$ & $10.65(5.64)$ \\
& Bigelow Beach & $4.38(3.23)$ & $2.82(4.34)$ \\
& Crab Cove & $5.40(2.73)$ & $3.90(4.38)$ \\
& Muskmelon Bay & $14.55(7.54)$ & $2.25(2.21)$ \\
Tortola & Brewer's Bay I & $2.15(0.49)$ & $19.50(19.24)$ \\
& Brewer's Bay II & $10.25(3.47)$ & $8.31(3.96)$ \\
\hline
\end{tabular}

Markers subdivided the site into a $2 \times 2 \mathrm{~m}$ lattice and, because bridled gobies occupy small home ranges $\left(<2.5 \mathrm{~m}^{2}\right)$, we were able to repeatedly locate fish within the site. Gobies $(n=425)$ were captured using the anesthetic quinaldine and hand nets, measured, tagged then immediately released (within $0.5 \mathrm{~m}$ of the site of capture) during 2 time intervals, 30 June to 14 July, and 4 to 7 August 2001. Sub-dermal tags allowed individual recognition of gobies: larger fish (>25 mm SL) received numbered plastic tags, and smaller fish (15 to $25 \mathrm{~mm} \mathrm{SL}$ ) received a unique combination of colored spots of silicone (tags available from Northwest Marine Technologies). Both tag types are harmless and can be viewed without capturing the fish (Forrester 1995, Malone et al. 1999). The entire site and surrounding habitat within $4 \mathrm{~m}$ was searched for tagged fish every 3 to $5 \mathrm{~d}$ until 19 August, and finally on 27 and 28 October 2001. The infection status of tagged fish was visually assessed at every resighting.

Behavioral observations were made on a random subsample of tagged parasitized $(\mathrm{n}=35)$ and uninfected fish $(n=34)$ from 15 to 25 July 2001. To minimize disturbance to the gobies, divers remained 1.5 to $2 \mathrm{~m}$ from the goby and remained still during the observation. Each fish was observed for $5 \mathrm{~min}$, during which time we recorded the feeding rate, the rate and outcome of aggressive interactions with conspecific neighbors, and the distance from the nearest shelter every $30 \mathrm{~s}$. The diver then moved closer and measured the gill ventilation rate over a $30 \mathrm{~s}$ period while the fish was not swimming or feeding. Behaviors of parasitized and uninfected gobies were compared using 2-sample $t$-tests assuming unequal variance.

While searching the site on 2 to 4 August 2001, we recaptured and remeasured haphazardly selected fish that had apparently remained infected $(n=19)$ or uninfected $(\mathrm{n}=49)$ since tagging. Daily growth rate was calculated using the change in length $(\mathrm{mm})$ from the date of tagging to recapture. We used analysis of covariance (ANCOVA) to test effects of parasitism on growth, with initial size as a covariate to account for the effects of size on growth (Sokal \& Rohlf 1995). We also assessed the relative reproductive output of female gobies with $(n=19)$ and without $(n=17)$ parasites by measuring gonad dry mass. These females were collected just outside the study area in August 2001 and the 2 groups were similar in body size (30.9 \pm $3.4 \mathrm{~mm}$ SL unparasitized, $29.7 \pm 3.7 \mathrm{~mm}$ SL parasitized, $\mathrm{df}=25, t=0.981, \mathrm{p}=0.336$ ). A 2 -sample $t$-test assuming unequal variance was used to detect differences in gonad mass. The entire site and the $4 \mathrm{~m}$ perimeter were searched every 3 to $5 \mathrm{~d}$ from 30 June to 19 August, and again on 27 and 28 October. Hence, we are confident that disappearance of tagged gobies was due to death rather than emigration. According to our 
visual surveys, some gobies apparently gained $(\mathrm{n}=48)$ or lost parasites $(n=33)$ during the study. We therefore generated survival curves for fish never parasitized $(\mathrm{n}=214)$, and fish parasitized on some or all dates on which they were observed $(\mathrm{n}=211)$. We used a simple exponential survival model because it fit the data as well as several more complex survival models (Lee 1992). Fish were tagged over several days and so we started tracking their survival on different calendar dates. However, we fit the survival model using the date of tagging as a common start date rather than starting from a specific calendar date.

To test whether goby density and the prevalence of infection were related, we censused the entire $560 \mathrm{~m}^{2}$ study area on 4 to 6 July 2001. Using the lattice of site markers, we subdivided the site into thirty-two $16 \mathrm{~m}^{2}$ plots. The relationship between density (the independent variable) and prevalence (the dependent variable) at this spatial scale was tested using linear regression, with the $y$-intercept forced through the origin.

Results. Parasitism affected some, but not all, of the goby behaviors we measured. Parasitized fish had a higher respiration rate and fed at lower rates than unparasitized fish (Table 2). Being parasitized did not, however, affect the mean distance to shelter, or outcome of aggressive interactions with conspecific neighbors (Table 2). All of the goby demographic responses we measured were strongly affected by parasitism. Parasitized female gobies had gonads that were significantly smaller than uninfected females of comparable body size (Table 2). To test for effects of parasitism on growth we used gobies spanning a range of body sizes. To account for possible effects of initial body size on growth, we used ANCOVA to test the effects of parasitic infection (a categorical effect), initial goby size (a covariate), and the interaction between infection and initial size on growth. Smaller bridled gobies grew faster than larger ones $\left(F_{1,64}=\right.$ 13.8, p < 0.0004), but the relationship between initial size and growth did not differ in slope for parasitized and unparasitized fish $\left(F_{1,64}=0.09, \mathrm{p}=0.76\right)$. More importantly, the analysis revealed a significant reduction in growth associated with parasitism $\left(F_{1,65}=25.6\right.$,

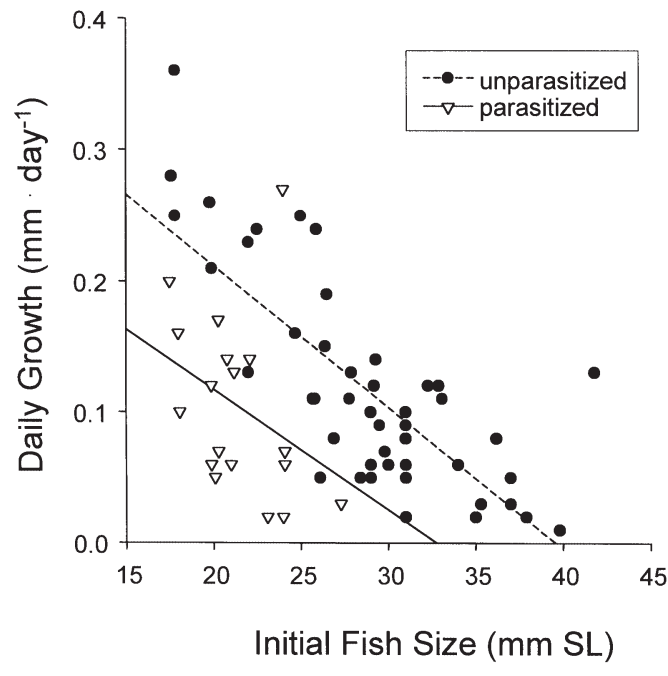

Fig. 1. Coryphopterus glaucofraenum. Growth rates of tagged unparasitized and parasitized gobies recaptured on 2 to 4 August 2001. Growth rate was significantly higher in unparasitized than in parasitized gobies, and was dependent on the size of the fish at tagging; see text for details

p $<0.0004$, Fig. 1). Goby mortality was also affected by parasitism. The instantaneous mortality rate of gobies infected with gill parasites for all or part of the study (0.024) was nearly twice as high as the mortality of parasite-free gobies (0.013). This parasite-induced increase in mortality was statistically significant (Fig. 2). Finally, goby density and Pharodes tortugensis prevalence were positively related, detected when the $560 \mathrm{~m}^{2}$ monitoring area was subdivided into $16 \mathrm{~m}^{2}$ subunits $\left(y=0.066 \mathrm{x}, \mathrm{r}^{2}=0.462, \mathrm{p}<0.001\right)$. At this spatial scale, the percentage of gobies with parasitic infections thus increases as the gobies become more crowded.

Discussion. Strictly speaking, we did not isolate the effect of parasitism because we simply correlated parasite presence with host responses, rather than experimentally infecting a random sample of hosts (Scott \& Dobson 1989). Other undetected factors might be the direct cause of the observed changes in goby behavior and demography if their influence is correlated with

Table 2. Coryphopterus glaucofraenum. Behavior and fecundity of parasitized and unparasitized gobies; means ( \pm SD) and results of $t$-tests comparing the 2 groups

\begin{tabular}{|lrrr|}
\hline & Parasitized & Unparasitized & $t$-test \\
\hline Feeding (bites $30 \mathrm{~s}^{-1}$ ) & $2.8 \pm 2.7$ & $4.5 \pm 3.6$ & $\mathrm{df}=67, t=2.208, \mathrm{p}=0.031$ \\
Respiration (gill ventilations $30 \mathrm{~s}^{-1}$ ) & $48.7 \pm 14.1$ & $29.4 \pm 8.2$ & $\mathrm{df}=67, t=6.938, \mathrm{p}<0.001$ \\
Aggression (losses $5 \mathrm{~min}^{-1}$ ) & $1.4 \pm 0.5$ & $1.6 \pm 0.8$ & $\mathrm{df}=12, t=0.397, \mathrm{p}=0.675$ \\
Aggression (wins $5 \mathrm{~min}^{-1}$ ) & $1.8 \pm 1.2$ & $2.3 \pm 1.9$ & $\mathrm{df}=8, t=0.435, \mathrm{p}=0.675$ \\
Distance to shelter $(\mathrm{cm}$ ) & $13.1 \pm 11.6$ & $13.5 \pm 9.3$ & $\mathrm{df}=67, t=0.186, \mathrm{p}=0.853$ \\
Relative reproductive investment (gonad dry weight, $\mathrm{mg}$ ) & $0.2 \pm 0.1$ & $0.6 \pm 0.5$ & $\mathrm{df}=28, t=4.065, \mathrm{p}<0.001$ \\
\hline
\end{tabular}




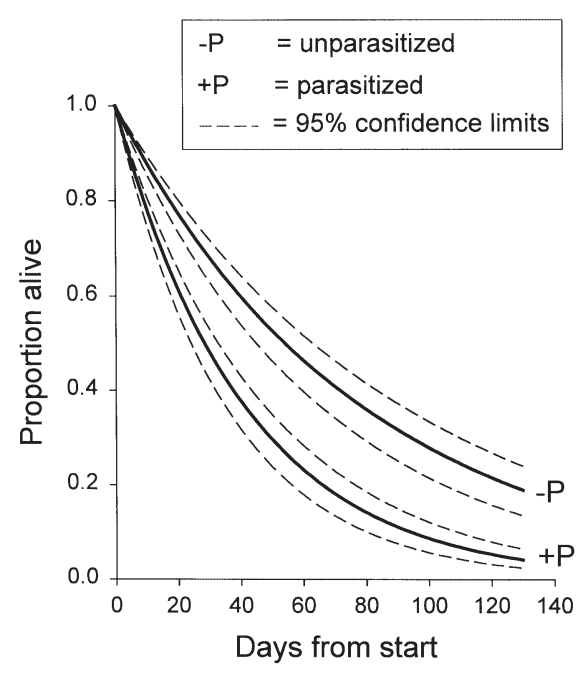

Fig. 2. Coryphopterus glaucofraenum. Survival curves for gobies parasitized some or all of the time $\left(y=\mathrm{e}^{-0.024 x}\right)$, and for gobies never parasitized $\left(y=\mathrm{e}^{-0.013 x}\right)$

parasite presence (Madhavi \& Anderson 1985, Schad \& Anderson 1985, Gulland et al. 1993). Offsetting the limitations of our correlational study design is the ability to track individual gobies of known infection status. Effects of parasites on wild host populations are often assessed using indirect methods, whose assumptions are difficult to verify (Grenfell \& Dobson 1995). Tracking individuals provided a simple direct measure of associations between ectoparasitism and host responses, and implied a striking impact of Pharodes tortugensis on bridled gobies. The one prior study of parasite impacts on reef fish, in this case of damselfish infected with ectoparasitic isopods, also reported demographic costs of parasitism (Adlard \& Lester 1994). Researchers studying reef fishes have argued that predation and competition account for most mortality (Sale 1991). Quantitative comparison of mortality rates among studies is difficult, but the approximate doubling of instantaneous mortality due to parasitism that we detected is roughly equal to the increase to mortality attributable to predation in predator-exclusion experiments on bridled gobies (Forrester \& Steele 2000, Forrester unpubl.). Agents of mortality need not be additive in their effect, however, and our findings raise the important possibility that parasitism in reef fishes may mediate vulnerability to predation (Hudson \& Dobson 1995).

Also central to the importance of parasites for host dynamics is their potential to cause density-dependent regulation (May \& Anderson 1979). Mortality in bridled gobies is spatially density-dependent at scales from 8 to $64 \mathrm{~m}^{2}$ (Forrester 1995, Forrester \& Steele unpubl.). In this study, goby density and Pharodes tortugensis prevalence were positively related at an equivalent scale $\left(16 \mathrm{~m}^{2}\right)$. A higher prevalence of parasitism at high goby density may thus lead to an increase in overall goby mortality in crowded areas within a site and so may regulate the goby population. This possibility is intriguing because cases of population regulation by macroparasites are quite rare, and macroparasites have been considered less likely to regulate host abundance than microparasites (May \& Anderson 1979, Dobson \& May 1987, Scott \& Dobson 1989, May 1993).

Acknowledgements. We thank C. D. Tran, B. Finley, and J. Messineo for field and laboratory assistance, plus L. Jarecki and the Guana Island staff for logistical support. Financial support to G.F. came from NSF (OCE 0096061) and the Falconwood Corporation. R.F. was supported by the International Women's Fishing Association.

\section{LITERATURE CITED}

Adlard RD, Lester RJG (1994) Dynamics of the interaction between the parasitic isopod, Anilocra pomacentri, and the coral reef fish, Chromis nitida. Parasitology 109: 311-324

Bertness MD, Gaines SD, Hay ME (2001) Marine community ecology. Sinauer Associates, Sunderland, MA

Caley MJ, Carr MH, Hixon MA, Hughes TP, Jones GP, Menge BA (1996) Recruitment and the local dynamics of open marine populations. Annu Rev Ecol Syst 27:477-500

Cole DS, Shapiro DY (1992) Gonadal structure and population characteristics of the protogynous goby Coryphopterus glaucofraenum. Mar Biol 113:1-9

Dawson LHJ (1998) The physiological effects of salmon lice (Lepeophtheirus salmonis) infections on returning postsmolt sea trout (Salmo trutta L.) in western Ireland, 1996. ICES J Mar Sci 55:193-200

Dobson AP, Hudson PJ (1992) Regulation and stability of a free-living host-parasite system: Trichostrongylus tenuis in red grouse. II. Population models. J Anim Ecol 61:487-198

Dobson AP, May RM (1987) The effects of parasites on fish populations: theoretical aspects. Int J Parasitol 17:363-370

Forrester (1995) Strong density-dependent survival and recruitment regulate the abundance of a coral reef fish. Oecologia 103:275-282

Forrester GE, Steele MA (2000) Variation in the presence and cause of density-dependant mortality in three species of reef fishes. Ecology 81:2416-2427

Grenfell BT, Dobson AP (1995) Ecology of infectious diseases in natural populations. Cambridge University Press, Cambridge

Grenfell BT, Gulland FMD (1995) Ecological impact of parasitism on wildlife host populations. Parasitology 111:S3S14

Gulland FMD, Albon SD, Pemberton JM, Moorcroft PR, Clutton-Brock TH (1993) Parasite-associated polymorphism in a cyclic ungulate population. Proc R Soc Lond B:254:7-13

Ho JS (1971) P. Wilson, 1935, a genus of cyclopoid copepods (Pharodidae) parasitic on marine fishes. J Nat Hist 5: 349-359

Hudson PJ, Dobson AP (1995) Macroparasites: observed patterns. In: Grenfell BT, Dobson AP (eds) Ecology of infectious diseases in natural populations. Cambridge University Press, Cambridge, p 144-176 
Hudson PJ, Dobson AP, Newborn D (1998) Prevention of population cycles by parasite removal. Science 282: 2256-2258

Kabata Z (1981) Copepods (Crustacea) parasitic on fishes: problems and perspectives. Adv Parasitol 19:1-71

Lee ET (1992) Statistical methods for survival data analysis. John Wiley \& Sons, New York

Lester RJG (1984) A review of methods for estimating mortality due to parasites in wild fish populations. Helgol Meeresunters 37:53-64

MacKenzie K, Longshaw M, Begg GS, McVicar AH (1998) Sea lice (Copepods: Caligidae) on wild sea trout (Salmo trutta L.) in Scotland. ICES J Mar Sci 55:151-162

Madhavi R, Anderson RM (1985) Variability in the susceptibility of the fish host, Poecilia reticulata, to infection with Gyrodactylus bulltarudis (Monogenea). Parasitology 91: 531-544

Malone JC, Forrester GE, Steele MA (1999) Effects of subcutaneous microtags on the growth, survival, and vulnerability to predation of small reef fishes. J Exp Mar Biol Ecol 237:243-253

Editorial responsibility: Charles Peterson (Contributing Editor), Morehead City, North Carolina, USA
May RM (1993) Parasitic infections as regulators of animal populations. Am Sci 71:36-45

May RM, Anderson RM (1979) Population biology of infectious diseases: Part II. Nature 280:455-461

Nolan DT, Reilly P, Wendelaar Bonga SE (1999) Infection with low numbers of the sea louse Lepeophtheirus salmonis induces stress-related effects in postsmolt Atlantic salmon (Salmo salar). Can J Fish Aquat Sci 53:947-959

Poulin R (1995) Phylogeny, ecology, and the richness of parasite communities in vertebrates. Ecol Monogr 65:283-302

Sale PF (1991) The ecology of fishes on coral reefs. Academic Press, San Diego

Schad GA, Anderson RM (1985) Predisposition to hookworm infection in humans. Science 228:1537-1540

Scott ME, Dobson A (1989) The role of parasites in regulating host abundance. Parasitol Today 5:176-183

Sindermann CJ (1987) Effects of parasites on fish populations: practical considerations. Int J Parasitol 17:371-382

Sokal RR, Rohlf FJ (1995) Biometry: the principles and practice of statistics in biological research. WH Freeman, New York

Submitted: November 28, 2001; Accepted: December 2, 2002 Proofs received from author(s): February 7, 2003 